\title{
Ética en la guerra: la distinción entre soldados y civiles
}

\section{(Ethics in war: the distinction between soldiers and civilians)}

\author{
Francisco LARA
}

Recibido: 28 de noviembre de 2012

Aceptado: 2 de julio de 2013

\section{Resumen}

La forma habitual de diferenciar la conducta debida, en un enfrentamiento bélico, a soldados y a civiles descansa en la prescripción universal de no matar, que, por un lado, debe regir estrictamente el trato a la población civil y que, por otro, admite la excepción de quitar la vida a combatientes enemigos como un acto de legítima defensa. El autor critica este planteamiento y esboza una manera diferente de entender y justificar la distinción moral entre soldados y civiles.

Palabras clave: ética de la guerra, principio de inmunidad de los no combatientes, defensa propia, consecuencialismo.

\section{Abstract}

In war a soldier behaving properly should take into account a universal requirement not to kill, to be applied strictly in dealing with civilians, but at the same time to support the exception of taking the life of enemy combatants as an act of selfdefense. This is the usual way to distinguish morally the proper treatment to soldiers and civilians. In this article the author criticizes it and outlines a different way to understand and justify the moral distinction mentioned.

Keywords: ethics of war, principle of noncombatant immunity, self-defense, consequentialism. 
Para nuestra moral tradicional no hay nada tan grave como quitarle la vida intencionadamente a un ser humano. De ahí que la prohibición de matar deje poco margen para las excepciones. Eso explicaría, por ejemplo, las reticencias de mucha gente a aceptar la práctica de la eutanasia como una de esas excepciones. Dicha práctica es ilegal en la mayoría de países a pesar de consistir en que un médico satisface el razonable deseo de un individuo de no seguir viviendo con una incurable enfermedad letal que provocará innecesarios y terribles sufrimientos a él y a sus seres queridos. La prohibición de matar se formula tan categóricamente que ni siquiera es motivo para desoírla la compasión ante un enfermo que agoniza en tan pésimas condiciones.

Sin embargo, en este contexto moral resulta extraño que haya una situación en la que matar no sólo se permite, sino que se exige. Me refiero a cuando un país se involucra en un conflicto bélico. Cuando eso ocurre, se da por hecho que la mayor parte de sus ciudadanos tienen la obligación de empuñar las armas para, si fuera preciso, matar de manera masiva a otros seres humanos. En tales circunstancias, desobedecer la regla "no matarás" no sólo no es motivo de censura moral, sino que puede ser objeto de condecoraciones, mientras que seguirla puede castigarse con la cárcel o la pena de muerte. Podría decirse entonces que por su amplia aceptación social y por el elevado número de víctimas que provoca, la guerra es la "la gran excepción" a la fuerte exigencia moral de no matar.

Por supuesto, esta excepción no se considera ilimitada. Por eso existe una ética de la guerra. Según esta, parece incuestionable que un Estado no puede declarar la guerra a otro siempre que quiera y obligar así a sus ciudadanos a coger las armas, poniendo en peligro sus vidas y las de muchos otros. Se ha defendido que sólo ciertas guerras son justas; por ejemplo, aquellas en las que con ellas se castiga a un país por haber hecho algo reprobable, muchas veces de tipo moral o religioso, o, desde una perspectiva más contemporánea, por hacer peligrar la paz entre Estados invadiendo (o disponiéndose a invadir) algún país. Estas causas que legitimarían una guerra han sido el principal objeto de estudio de lo que se conoce como ius ad bellum. Pero también se ha reflexionado sobre los límites morales de la guerra en lo que respecta no a su legitimidad, sino al comportamiento de los individuos que participan en ella. Este último sería el ámbito del ius in bello, el que me interesa tratar en este artículo. Desde este ámbito siempre se ha sostenido que una de las principales exigencias que ha de cumplir todo soldado, si quiere comportarse moralmente, es la de no matar indiscriminadamente. En su compromiso de contribuir a la victoria de su ejército, al soldado se le permite, entonces, realizar acciones que pretendan la pérdida de combatientes enemigos, pero, en ningún caso, de civiles. Este permiso restringido es lo que, en la literatura especializada, se conoce como "principio de distinción entre combatientes y no combatientes" o "de inmunidad de los no combatientes". En adelante, nos referiremos a él como "principio de inmunidad". 
¿Y cómo se justifica este principio, que diferencia entre combatientes y no combatientes, en un marco de defensa del derecho universal a la vida? La justificación de dicho principio se ha abordado tradicionalmente, y se aborda en la actualidad, desde el concepto de defensa propia. Eso, en principio, tiene sentido. En términos de nuestra moral cotidiana, y de nuestras leyes en tiempos de paz, entendemos que la excepción más aceptable a la prohibición de matar se da cuando alguien quita la vida de otro para evitar que este le mate. Se suele aceptar que si alguien inmediatamente pone en serio peligro tu vida y sólo puedes salvarte quitando la vida de él, entonces hacerlo no es propiamente una violación de esa prohibición básica de matar; o que si lo es, merece ser excusada. Pues bien, se afirma que en la guerra sería igual, que esa gran excepción a la regla de no matar, que supone la guerra, se justifica finalmente en términos de defensa propia. Y que, por el contrario, matar intencionadamente a la población civil no sería ningún acto de legítima defensa porque los desarmados civiles, se dice, no ponen en riesgo la vida de nadie.

En definitiva, el comportamiento debido de un soldado hacia los combatientes y no combatientes enemigos se justifica en virtud de una "analogía doméstica"1, que reduce las reglas de la guerra a las reglas de la defensa propia personal en tiempos de paz ${ }^{2}$. El objetivo primordial de este artículo es cuestionar esta justificación tradicional del principio de inmunidad en virtud del concepto de defensa propia. Para ello argumentaré que desde las dos interpretaciones más extendidas de este concepto en la moral cotidiana, resulta muy difícil defender el principio inmunidad. Un segundo objetivo será esbozar una justificación de dicho principio desde un marco teórico distinto.

\section{Defensa propia en términos de culpabilidad}

La cuestión clave a la hora de legitimar la defensa propia es por qué los defensores tienen permiso para matar a los agresores cuando se parte de un marco normativo en el que el derecho a la vida es universal y de cuya titularidad no están excluidos, en un principio, ni siquiera los agresores. La forma predominante en los últimos veinte años de explicar ese permiso excepcional para matar sostiene que cuando alguien pone en peligro tu vida, él es el único culpable de la situación, y que, por ello, dado que hay que elegir entre dos vidas, la tuya es moralmente prioritaria

\footnotetext{
1 Aunque ya es de uso compartido en la bibliografía especializada, la expresión es originaria de Walzer (1977, p. 97), uno de los principales representantes de la doctrina contemporánea de la guerra justa.

2 La justificación de la guerra misma también suele acudir al concepto de defensa propia. Así, se mantiene que todo Estado puede usar la fuerza militar en la defensa de su soberanía frente a la invasión de otro Estado, de la misma manera que un individuo que es atacado tiene derecho a matar en defensa propia. Véase, por ejemplo, Walzer (1977, cap. 4).
} 
porque, a diferencia del atacante, tú eres inocente. En definitiva, puedes matar al otro porque este es culpable de querer violar la regla básica de no matar o-también se puede decir así- tu derecho a la vida3 .

Creo que esta explicación de la defensa propia en el ámbito doméstico ha sido la predominante por ser la más intuitiva. Sin embargo, no sirve para justificar el comportamiento diferenciador que con el principio de inmunidad se exige. Esto es, desde tal concepción de la defensa propia resulta muy difícil sostener tanto que todos los soldados enemigos son legítimos destinatarios de mis ataques, como que ningún civil lo puede ser.

Respecto a la dificultad de esta propuesta para legitimar el atentar contra la vida de cualquier soldado enemigo nos encontramos con una seria dificultad. Pues si la razón por la que yo podría matar a un soldado enemigo es por su culpabilidad de poner en peligro mi vida, nos encontramos con el problema de que ese soldado enemigo puede realmente no ser culpable de amenazarme, dado que él puede estar enfrentándose a mí por coerción, compulsión, manipulación o ignorancia. Desde esta perspectiva, entonces, quitarle la vida a un soldado enemigo de este tipo podría ser un acto excusable en términos de propia supervivencia, pero nunca un acto moralmente justificable 4 .

\footnotetext{
${ }^{3}$ Esta forma de entender la defensa propia, en particular como una propuesta de interacción entre derechos en una situación de conflicto violento, es planteada en Rodin (2003) y (2008), y Draper (2009). Para Rodin (2004), uno puede matar a un agresor homicida para defenderse en virtud de que este, por ser culpable del ataque, ha perdido su derecho a no ser matado (p. 64). Alexander (1987) y (1993) y Ferzan (2005) también basan su propuesta en la culpabilidad, pero sin recurrir a la idea de derechos. Un esquema muy similar podría sostener que es la injusticia de que te amenacen, más que propiamente la culpabilidad del agresor, lo que hace legítima la defensa. Esto es lo que mantienen, por ejemplo, Montague (1981), (1989), (2000) y (2010); Otsuka (1994) y McMahan (1994a), (2002), (2005a) y (2005b). McMahan plantea el tema en términos de responsabilidad más que de culpabilidad. Así, para él es correcto matar a una persona en defensa propia cuando esta es responsable de una injusta amenaza a tu vida. La diferencia con la propuesta de la culpabilidad está en aquellos casos en los que tú eres responsable de una amenaza sin ser culpable de ella. Por ejemplo, tú conduces con cuidado pero te encuentras con una placa de nieve que hace que te dirijas irremediablemente hacia un peatón que morirá. El peatón puede salvarse destruyendo tu coche y, con ello, a ti. McMahan afirma que eres responsable de una injusta amenaza hacia él. Eres responsable porque te has embarcado en una actividad, la de conducir, que tú sabes que pone en riesgo a los peatones. Porque tú eres responsable de la amenaza y porque esta no es justa, McMahan cree que el peatón puede matarte en este caso. Ya que no eres culpable del accidente, ninguna propuesta de la culpabilidad concurre. McMahan se alejó de una propuesta de la culpabilidad en parte para acomodar su juicio sobre este caso. Para críticas a los tipos de propuestas de defensa propia mencionados en esta nota, véanse Benbaji (2005), Kaufman (2009), Tadros (2009) y Wallerstein (2009).

${ }^{4}$ La crítica a esta propuesta resulta, sin embargo, mucho más contundente si nos percatamos de que la analogía doméstica no funciona bien con respecto a una situación en la que estuviéramos ante unos soldados enemigos que son responsables de la guerra (injusta) y que han ido a ella convencidos y con entusiasmo. En la guerra se parte de una simetría de la defensa propia entre soldados, e incluso desde el bando contrario se puede entender que los soldados de la causa injusta se vean a sí mismos, y desde
} 
Por otro lado, la propuesta también se enfrenta a serios problemas para concluir de manera contundente que, desde una concepción de la defensa propia en términos de culpabilidad, todos los no combatientes son inmunes a la acción homicida de los militares. Muchos de los civiles son culpables, incluso más que muchos soldados, de que se haya declarado la guerra, y además pueden colaborar activamente con el ejército. A pesar de ello, es cierto que tales civiles, en tanto que están desarmados, no son una amenaza directa para ti, y en ese sentido no se les podría matar en defensa propia. Igual que tampoco se acepta que en el ámbito doméstico sea defensa propia el matar a un mero espectador o "transeúnte" (como se denomina en la literatura especializada) sólo porque, por ejemplo, haya deseado tu muerte, haya suministrado alimentos al agresor o incluso haya fabricado el arma de este. No obstante, el problema reside en que los propios postulados de la propuesta son incapaces de impedir a veces un deslizamiento hacia permitir que se mate en defensa propia a los transeúntes $\mathrm{y}$, por tanto, a ciertos no combatientes. Veámoslo en el análisis del siguiente caso.

Supongamos que, en un contexto no bélico, Pablo es un agresor inocente que injustamente quiere matarte, pero que no es culpable de ello. Le mueven falsas creencias sobre ti, que podrían justificar tu muerte de ser ciertas. Pero él no es culpable de tener estas creencias, pues se las inculcó Luis, por medio del engaño y con la intención de que, por ellas, Pablo te matara. Pero ahora Luis no está haciendo nada que amenace tu vida. A pesar de ello, parece que tú tienes un derecho a no ser matado en estas circunstancias, un derecho que Pablo está violando. Imaginemos que dos cursos de acción, cualquiera de los cuales salvaría tu vida, son posibles. Podrías matar a Pablo, el agresor inocente, y así evitarías que te mate. O bien, podrías matar a Luis, lo que turbaría a Pablo lo suficiente como para que fuera incapaz de matarte. También cabe modificar el ejemplo de modo que en vez de Luis, culpable en el pasado de que ahora alguien te quiera matar, hablaríamos de Juan, que no amenaza directamente tu vida pero que anima a Pablo para que te mate, y que si no colabora efectivamente con él, es porque no puede. Igualmente, en este otro caso para salvar tu vida puedes matar a Pablo, el agresor inocente, o a Juan, el transeúnte culpable.

En ambos casos, cualquier plausible teoría sobre el homicidio justo basada en la culpabilidad aprobaría matar a Luis o a Juan para salvar tu vida. Los hechos pertinentes son que, por un lado, Luis ha contribuido a provocar la situación en la cual tu vida está en peligro y, por otro, Juan anhela tu muerte y hace, infructuosamente,

su sociedad, como cumpliendo un noble deber, más que como criminales. Por eso, a los prisioneros de guerra que hayan manchado sus manos de sangre no se les castiga propiamente (a no ser que sean oficiales); se les exime de sus homicidios en el campo de batalla porque se considera que, a pesar de combatir por una causa injusta y de hacerlo con convencimiento, mataron en defensa propia. Esto no ocurre, sin embargo, en el ámbito doméstico, cuando, por ejemplo, un atracador para defender su vida atenta contra la del policía que está a punto de dispararle. En este caso, no exculpamos al atracador aduciendo que mató en defensa propia. 
todo lo que puede para que Pablo te mate. Tanto Luis como Juan, aunque en distinto grado, son moralmente culpables de que tu vida esté amenazada, y resulta que tu darles muerte evitaría la amenaza. Aún cuando ni Luis, ni Juan, supongan, actualmente en un caso y efectivamente en el otro, una amenaza para tu vida, no por ello pueden ser inmunes al daño. Si en estos dos casos no hay más remedio que elegir entre tres vidas, dos de ellas de inocentes, la del agresor y la tuya, y una de un culpable, la de Luis o Juan, habría que elegir la del culpable que no me amenaza, esto es, la del transeúnte. Esa es la lógica consecuencia de esta propuesta de la defensa propia.

A esa consecuencia también se llega si aplicamos esta propuesta al ámbito de la guerra. Consideremos a un espía trabajando para los aliados en la Alemania nazi durante la II Guerra Mundial ${ }^{5}$. Resulta que el espía puede realizar dos homicidios que contribuirían igualmente al éxito de la misión. En uno de ellos puede matar a un joven soldado que, por haber sido educado desde pequeño para no cuestionar la autoridad civil, cree que está haciendo lo correcto sirviendo en el ejército alemán. Él no es culpable de tener esta creencia, de modo que no se le puede reprobar moralmente su actividad militar. El otro homicidio tendría como objetivo un civil, alguien que no se dedica a ninguna actividad bélica. Pero este civil es un malvado nazi que trabajó fervorosamente para que Hitler alcanzara el poder, y para consolidar su régimen autoritario. O si no lo hizo, ahora está muy entusiasmado con la causa nazi, tanto que si no fuera por una discapacidad que padece, formaría parte del ejército alemán. Parece que según esta propuesta de defensa propia, estarías moralmente obligado a matar al civil culpable antes que al combatiente no culpable. Si para conseguir la misma importante ventaja en la contienda alguien debe morir, mejor elegir entonces al promotor o simpatizante de la injusta causa, y no a quien no puede ser acusado de ello. Dicha elección sería vinculante para esta propuesta aún cuando aquel, de hecho, no amenaza con matar a alguien, cuando se trata, por tanto, de un simple transeúnte6.

\section{Defensa propia en términos de amenaza}

Estos problemas, que se le plantean al intento de justificar desde la defensa propia la distinción moral de combatientes y no combatientes, podrían evitarse, no obs-

\footnotetext{
5 Estos casos imaginarios provienen, después de considerables modificaciones, de Arneson (2006, pp. 107-110).

6 Sobre este inevitable deslizamiento que lleva a las teorías de la culpabilidad a tener que aceptar el matar a transeúntes, véase McMahan (2005a) y (2005b). Tadros (2009) sostiene, sin embargo, que esta objeción también se le puede formular a la propuesta de McMahan, basada más en la responsabilidad de la amenaza injusta que en la culpabilidad. Véase nota 3 de este artículo.
} 
tante, si ponemos el acento más en el carácter amenazante de la acción que en la culpabilidad. La plausibilidad de esta estrategia vendría de lo intuitivo de que si alguien pone en peligro tu vida siendo tú inocente, no tienes por qué resignarte a morir, con independencia de si el otro es o no culpable de la situación? Consideremos el caso de una persona que me ataca motivada por una alucinación producto de su enfermedad mental. Ya que ni la enfermedad, ni sus efectos, son propiamente una elección consciente suya, dicha persona puede ser considerada un agresor inocente. No obstante, desde esta otra propuesta, en la que la culpabilidad no es lo decisivo, se refuerza la idea, también de sentido común, de que a pesar de la inocencia del atacante enfermo, yo estaría en mi derecho de usar fuerza letal si esta es la única manera de salvarme. Pero no sólo sería legítimo entonces defenderse quitando la vida del atacante en el caso de que este sea una persona demente, sino que también lo sería ante todo aquel que, sin pretenderlo conscientemente, sea una amenaza directa contra la vida de uno. Como, por ejemplo, quitándosela a una persona que, sin culpa suya, está cayendo sobre mí. Cuando se presenta este conocido caso, se estipula que si yo no hago nada, amortiguaré el impacto y moriré, mientras que la persona que cae sobre mí se salvará. Igualmente se pide que aceptemos, por mor de la argumentación, que yo no tengo la opción de hacerme a un lado y que, por tanto, mi salvación depende exclusivamente de que yo mate a la persona que cae, utilizando -dependiendo de la versión del caso- un toldo que le hará desviarse o una sofisticada arma que desintegrará su cuerpo. Desde esta propuesta que consideramos ahora, donde la culpabilidad del atacante no es lo decisivo, quitar la vida tanto del loco, como de la persona que cae sobre mí, podría ser un caso de legítima defensa.

Es importante señalar, no obstante, que esta propuesta no es, aunque lo parezca, un alegato de la propia supervivencia. Esto es, no mantiene que en cualquier situación de necesaria elección entre vidas, un agente podría salvar la suya matando a otro incluso cuando este no la pone en peligro ${ }^{8}$. Así, propiamente no sería legítima defensa, por ejemplo, matar a alguien para que me sirva de alimento y no morirme de hambre si esa es la única forma de salvarme; ni tampoco lo sería, cuando no dándose otra opción, yo usara a alguien que está a mi lado como escudo para evitar que una jabalina atravesase mi cuerpo. En estos casos, en los que yo quitaría la vida de "transeúntes" para salvarme, no ocurriría como con el agresor inocente, que con su muerte elimino la fuente del peligro al que me enfrento. Ni quien me serviría de alimento, ni aquel a quien usaría de escudo son realmente amenazas para mi vida.

\footnotetext{
7 Representantes de esta otra forma de concebir la defensa propia son Thomson (1991), Uniacke (1994), (2000a) y (2000b), Kadish (1976), Benbaji (2005), Leverick (2006), Draper (2009), Kamm (1992), Quong (2009) y Frowe (2008).

8 Thomson (1991, p. 298).
} 
También es un claro síntoma de que estamos ante una teoría moral, y no ante una simple defensa de la supervivencia, que la propuesta normalmente se formule en términos de derechos. Se argumenta que el agresor, por poner en peligro mi vida, porque va a violar mi derecho a no ser matado, pierde en ese mismo instante su derecho, que toda persona tiene en un principio, a que no se le quite la vida. En ese sentido es absolutamente irrelevante que no sea culpable de amenazarme letalmente. Pierde su derecho sólo por el acto en sí de amenazar la vida de otro, independientemente de si lo hace libre e intencionadamente. El poner en peligro la vida de otro crea una asimetría moral entre el atacante y la víctima basada no en la culpabilidad, sino en una responsabilidad meramente causal, que justifica que el agresor pierda su derecho a no ser matado9 ${ }^{9}$ Ahora bien, la situación es distinta en el caso de los "transeúntes", quienes, por no constituir una amenaza para mí, al no ser la causa de mi mal, retienen su derecho a no ser matados para salvarme yo.

Este planteamiento parece evitar entonces las dificultades que se le presentaban al de la culpabilidad cuando lo transferíamos a la ética de la guerra. Pues además de justificar la inmunidad de los civiles, en virtud de su equivalencia a los "transeúntes" de la analogía doméstica, este planteamiento podría dar razones para permitir que se matara en defensa propia a cualquier soldado enemigo porque, independientemente de su culpabilidad, es un agresor. Podría así justificar que se quite la vida de los agresores inocentes, de aquellos soldados que, aunque sea por coerción, compulsión, manipulación o ignorancia, pertenecen al ejército enemigo y que, por ello, son una amenaza para la vida de uno. En definitiva, los soldados perderían su derecho a no ser matados simplemente por su dedicación a combatir, y no por alguna falta o culpabilidad.

\section{Defensa propia y responsabilidad colectiva}

El primer problema de esta propuesta de la defensa propia basada en el carácter amenazante de los soldados, y no en su culpabilidad, es el hecho de que, en realidad, no todos los soldados enemigos suponen una amenaza seria para la vida de uno. ¿Cómo puede considerarse un acto de defensa propia el matar a soldados enemigos que en ese momento no me están atacando, o bien nunca me van a atacar porque, por ejemplo, son cocineros o mecánicos?

Una solución es concebir la defensa propia en un contexto bélico de soldados enfrentados que se relacionan no como individuos, sino como agentes colectivizados. Esto es, se puede proponer que el permiso para matar a los soldados enemigos que no me atacan derive no de aquello de lo que son individualmente responsables, sino de su pertenencia a la clase de los soldados del país que nos están atacando.

9 Thomson (1991, pp. 286, 293-4 y 298-9). 
Desde esta interpretación, la guerra es descrita y percibida correctamente sólo cuando la vemos como enfrentamiento entre dos naciones en vez de entre dos grupos de soldados individuales. Pero las naciones actúan a través de sus soldados y sólo es posible reaccionar atacando a esos soldados. Como individuos, estos podrían no ser merecedores de quitarles la vida en defensa propia, ya que muchos de ellos no nos están atacando. No obstante, dado que supuestamente nosotros, como nación, no estamos equivocados al hacerles la guerra a ellos, podríamos luchar contra sus soldados como nación, como miembros del ejército de la nación enemiga. Desde esta perspectiva, los soldados de dicha nación, al integrarse en el ejército, y al constituir este una amenaza para los soldados del otro bando, habrían perdido sus derechos individuales a no ser matados. Hagan lo que hagan individualmente (reparar aviones, cocinar...), su agencia ha sido nacionalizada y han dejado de obrar como individuos. Su responsabilidad, en cuanto amenazadora de mi vida, ya es colectiva ${ }^{10}$.

Este intento de mejorar la propuesta recurriendo a la colectivización de responsabilidades conlleva una robusta concepción de la nación que sólo tiene sentido desde postulados comunitaristas, difíciles de aceptar desde el individualismo imperante en la teorización sobre la evaluación moral. ¿Realmente podemos asumir que por vestir un uniforme, muchas veces coercitivamente, ya alguien es responsable de todos los males que los gobernantes u otros soldados puedan ocasionar? ¿Cómo puede ser visto como una amenaza real para mi vida un cocinero del ejército enemigo si no es presuponiendo una concepción metafísica del colectivo armado al que pertenece este? Además, desde esta interpretación colectivista de la defensa propia resultaría difícil mantener la distinción moral, supuesta en este debate, entre combatientes y no combatientes. Los defensores de esta propuesta suelen creer que si bien en nuestro buen proceder con civiles, sea en tiempo de paz o de guerra, prevalece la perspectiva individualista, de modo que podemos quitarles su vida en defensa propia sólo cuando individualmente amenacen la nuestra, con respecto a los soldados la perspectiva colectivista ha de ser determinante. Estos sí podrían ser matados aún cuando individualmente no nos amenacen seriamente. Si es así, entonces habría que justificar que sólo sean los soldados, y no los civiles, quienes queden subsumidos por la identidad colectiva en caso de guerra. Pero esto no es fácil cuando los civiles también forman parte de la nación y, de hecho, muchos de ellos se dedican en época de guerra, muchas veces con gran ahínco y convencimiento, a

\footnotetext{
10 Esto es lo que mantienen, por ejemplo, Walzer (1985) y Zohar (1993). Así, Walzer aplica su propuesta de la defensa propia sólo a las acciones de los Estados en lucha, no a las acciones de los individuos combatientes. De hecho, Walzer (1985) no cree que estos últimos requieran justificación de sus acciones porque no los considera agentes morales independientes de sus Estados. Sostiene que la agencia de la persona es nacionalizada cuando llega a ser un soldado (p. 35). Por ello, mantiene que "la guerra en sí misma no es una relación entre personas sino entre entidades políticas y sus instrumentos humanos" (p. 29).
} 
tareas para la logística de la contienda que pueden ser tan decisivas como las de muchos soldados. ¿Por qué entonces la actitud ante ellos debe ser tan distinta? ¿Por qué sólo la pertenencia al ejército es tan decisiva?11

\section{Soldados y civiles obstructores}

No obstante, las principales objeciones a la propuesta de la defensa propia en términos de amenaza no van dirigidas a ese intento de colectivización de la responsabilidad; tienen que ver sobre todo con los propios fundamentos de la propuesta. En esta se sostiene que la defensa propia radica en una pérdida de derechos del que te amenaza simplemente porque te amenaza, independientemente de su culpabilidad. Así es como se justifica que yo pueda legítimamente quitar la vida a un agresor inocente que pone en peligro la mía, pues al atentar contra mí pierde inmediatamente su derecho a no ser matado. Pero ¿cómo puede perder un derecho tan importante quien no es un agente propiamente? ¿Cómo se le puede quitar un derecho a quien, por no ser consciente de lo que hace, ni buscarlo intencionadamente, no merece perderlo? Si quien me amenaza pierde su derecho porque va a violar el mío, ¿cómo puede una persona realmente violar mi derecho si lo hace de manera no deliberada, por accidente, por ignorancia, por incapacidad mental o incluso, pasivamente, cuando cae sobre mí sin ningún control o agencia? Creo que conforme más se hace hincapié en que para esta propuesta la mera amenaza de alguien es razón suficiente para la defensa letal, más se pone de manifiesto que la propuesta responde finalmente a una exigencia de propia supervivencia, comprensible e intuitiva, pero muy alejada de la imparcialidad que requiere una evaluación moral de los actos.

11 Walzer (1985) reconoce que ya que, según él, los Estados tienen derecho a hacer la guerra en defensa propia, y ya que los Estados encarnan a sus ciudadanos, lo coherente sería concluir que todos los ciudadanos de los Estados en guerra podrían ser objetivos de la conducta bélica. Pero para Walzer tal inferencia es errónea. Para él, sólo los soldados pueden ser matados en defensa propia porque ellos, a diferencia de los civiles, están materialmente implicados en amenazar las vidas y libertades de los soldados enemigos. Sean o no voluntarios, todos los soldados han llegado a ser personas peligrosas. La culpabilidad moral no es relevante aquí. Asume que finalmente todos los soldados, de cualquier bando, luchan compelidos por el Estado para convertirse en homicidas. Los civiles, sin embargo, aunque hayan sido causalmente responsables de la guerra, no han perdido sus derechos de no ser matados porque al no participan en las actividades bélicas, no pueden ser considerados amenazas reales (p. 146). Pero habría que preguntarse, en términos exclusivamente de amenaza, si no puede ser tan amenazante un civil que ha sido movilizado para fabricar armas como un cocinero que prepara la comida a los soldados que usan dichas armas. En ese sentido, autores como McMahan (1994b) argumentarán que incluso cuando pensamos en la nación como un colectivo, la responsabilidad de sus acciones debe ser distribuida según la responsabilidad individual en los actos colectivos. Esto lleva a McMahan a negar que la división entre individuos según su participación en la responsabilidad colectiva coincida con la distinción entre combatientes y no combatientes (pp. 211-3). 
Por otro lado, tampoco está claro que esta propuesta pueda ser, a diferencia de la basada en la culpabilidad, una garantía para la protección de los no combatientes. Para demostrarlo volvamos al problema de cómo incorporar como víctimas potenciales de la defensa propia a los soldados no atacantes. Es decir ¿cómo puedo sostener que es un acto de defensa propia el matar a cualquier soldado enemigo, incluidos los que se dedican exclusivamente a la logística o están en la reserva? Sin recurrir a explicaciones colectivistas, que conllevan, como hemos visto, sus propias dificultades, esta propuesta basada en la amenaza sólo podría superar dicho problema si concibe a tales soldados enemigos como individuos que, aún no atacándome directamente, ni dedicándose a acciones ofensivas, constituyen una amenaza para mí en el sentido de que, en algún momento decisivo, podrían impedir que tomase alguna ruta o maniobra de escape ${ }^{12}$. Serían, por tanto, soldados "obstructores". Aunque cuando les ataquemos no estén haciendo nada que haga peligrar nuestras vidas, muchas veces porque ni siquiera sea esa su función, constituyen, sin embargo, amenazas pasivas capaces de dificultar acciones militares nuestras, conllevando así un riesgo similar al de algo que obstruye físicamente nuestra salvación ${ }^{13}$. A esto se le podría objetar que si esta es la única forma de introducir a todos los combatientes en la clase de los individuos que pueden ser matados en defensa propia, entonces lo hacemos al precio de incluir también a muchos no combatientes. Veamos cómo.

En el ámbito doméstico está claro que un transeúnte que te obstruye el paso puede ser tan amenazante para tu vida como lo sería que un compinche de tu agresor taponara tu vía de escape. Así, para el planteamiento de la defensa propia en términos de amenaza, entendiéndola en el sentido también de amenaza pasiva al que nos referimos más arriba, si alguien está casualmente aparcado en el arcén, que es tu única escapatoria de quien te persigue por una estrecha carretera para matarte, tú podrías legítimamente arrollar al que está aparcado con independencia de si es o no de la banda del agresor. Lo significativo es que, en términos de obstrucción, tan grave es el comportamiento del compinche como el del que no es de la banda. El

\footnotetext{
12 N. Zohar (2004, pp. 744-5).

$13 \mathrm{~N}$. Zohar (2004) considera que los obstructores no muestran diferencias morales significativas con respecto a los agresores inocentes. Ilustra esta afirmación con variaciones del caso de la persona que cae sobre mí. Pide que imagines que estás atrapado entre el cuerpo de una persona y una placa de metal. En un escenario posible, la placa está fija y la persona se está moviendo hacia ti hasta aplastarte contra la placa. En el otro escenario, la persona está fija y es la placa la que se mueve hacia ti. En ambos casos el objeto que se mueve es peligroso sólo por la presencia del objeto fijo. Aún así, la persona fija es tradicionalmente llamada un transeúnte a quien no sería permisible matar, mientras que la que se mueve es identificada como una amenaza inocente a quien esta propuesta de defensa propia permite matar. Zohar mantiene, sin embargo, que no hay ninguna plausible forma de distinguir entre la persona que se mantiene fija, el obstructor, y la que se mueve. Ambas serían lo que Zohar llama "amenazas pasivas".
} 
problema está en que el que no es de la banda puede ser considerado perfectamente un transeúnte.

Este mismo deslizamiento en el ámbito doméstico, que extiende la defensa propia primero hasta la muerte de los obstructores de la banda del agresor y, después, hasta los obstructores transeúntes, también es fácil de apreciar en el ámbito de la guerra. Si nos fijamos en el conflicto palestino-israelí, vemos cómo muchos civiles palestinos esconden a miembros de su ejército, y cómo otros civiles israelíes ocupan territorios del enemigo. Y resulta que en términos de contribución individual al desarrollo del conflicto, parece difícil señalar alguna diferencia esencial entre las contribuciones de tales civiles y las de los soldados cuya función no es la de disparar. A veces, incluso las contribuciones de aquellos pueden obstaculizar más seriamente que las de los soldados logísticos la actividad militar del enemigo. Lo importante es, no obstante, que en ambos casos (de civiles cooperadores y de soldados logísticos) hay una colaboración con los soldados agresores que puede ser vista como amenaza pasiva. Por tanto, desde esta propuesta de la defensa propia, una vez que matar en defensa propia se ha extendido a los soldados enemigos en general, es fácil extenderla también a algunos civiles. En otras palabras, pensar la amenaza que justificaría la defensa propia en términos de obstrucción o amenaza pasiva supone ampliar tanto el grupo de los que ponen en riesgo mi vida que acaba abarcando también a la población civil. Siendo así, serían una amenaza para mí no sólo las personas que se dedican a matar, sino también las que pueden obstruir una ruta de escape o las que conspiran con quienes van a matarme. En ese caso, los límites de la clase de los merecedores de muerte en defensa propia ya no coinciden, como se pretendía, con los límites del grupo de los combatientes. Los civiles, en calidad de potenciales colaboradores de los agresores, también podrían ser legítimos objetivos de los ataques ${ }^{14}$.

\section{La utilidad del principio de inmunidad}

Hemos visto que justificar el principio de inmunidad de los no combatientes a partir de la idea de defensa propia presenta serias dificultades. Tanto si interpretamos la defensa propia en términos de culpabilidad, como de amenaza, resulta complicado distinguir moralmente la conducta que es debida, en tiempos de guerra, a soldados y a civiles. Aún así, creo que esto no debe hacernos prescindir del principio. En lo que queda de artículo voy a aportar razones para seguir defendiendo el principio de inmunidad como parte importante de la ética del soldado, pero, eso sí, siempre que se asiente sobre fundamentos más sólidos.

Para ello conviene empezar precisando cómo hemos de entender el principio de inmunidad. Básicamente se trata, por supuesto, de exigir que el soldado, cuando

14 Algo similar, refiriéndose al conflicto palestino-israelí, sostiene N. Zohar (2004, pp. 744,748). 
participe en una guerra, diferencie moralmente entre combatientes y no combatientes enemigos, de modo que se sienta obligado a no atentar contra los últimos. Ahora bien, eso no significa que el soldado que se comporte correctamente no pueda en ningún caso provocar la muerte de civiles. Quien se tome en serio la moralidad de este tipo de situaciones no puede dejar de reconocer que ciertos ataques a objetivos militares pueden conllevar el resultado no deseado de la muerte de civiles. Esto es ineludible en la guerra moderna. El carácter mucho más sofisticado del armamento actual no garantiza, dado su gran potencial destructivo, respetar con estricta precisión la línea de demarcación entre combatientes y no combatientes. Por tanto, en aquellas situaciones en las que la guerra sea estrictamente necesaria para evitar males mayores -situaciones realmente infrecuentes si nos percatamos de los trágicos efectos de todo conflicto bélico-, la muerte colateral de inocentes puede ser inevitable. Esto supone conceder un papel destacado a la intencionalidad del agente, que la interpretación tradicional del principio de inmunidad siempre ha fundado en la conocida doctrina del doble efecto. Para esta, uno es sobre todo responsable de los efectos buscados, sean como fines en sí mismos o como medios para algún fin, pero no lo es tanto de los meramente previstos. Coincidiríamos entonces con esa interpretación tradicional del principio de inmunidad en la que este debe entenderse como la exigencia de que el soldado no quite deliberadamente la vida de los no combatientes. Así, aún cuando uno esté obligado a hacer todo lo posible por minimizar las pérdidas de civiles, a uno no siempre le estaría prohibido llevar a cabo acciones militares que conllevasen la muerte (no intencionada) de civiles.

Aquí acaban, no obstante, mis concesiones a la forma tradicional de entender el principio. A continuación criticaré sobre todo el modo en que se ha justificado. Se ha hecho partiendo de la idea de que hay algo intrínsecamente incorrecto en la acción de atentar deliberadamente contra la vida de una persona (inocente). Dicha acción manifiesta, se dice, una actitud irrespetuosa ante esa persona, al tomar una decisión sobre algo tan importante para ella, como es su vida, sin contar con ella. Esta sería la razón por la que no debemos atentar contra los no combatientes. En el caso de los enemigos combatientes, sin embargo, quitarles la vida intencionadamente sería una excepción a la regla que se justificaría en términos de defensa propia. Hemos visto, en la primera parte de este artículo, cómo esa forma de justificación de la excepción es problemática. Pero también lo es la propia justificación del criterio general de que la incorrección de matar intencionadamente reside en una falta de respeto hacia la víctima. Pues ¿no es también una falta de respeto a las víctimas inocentes de mi obrar el provocarles conscientemente, aún cuando no lo pretendamos, una muerte evitable? 15

15 Lichtenberg (1994) desarrolla un extenso argumento para criticar el uso tradicional de la doctrina del doble efecto en el ius in bello, insistiendo en que la mera diferencia entre pretender y no pretender 
Propongo, por tanto, que la diferenciación moral entre soldados y civiles no se base en características intrínsecas de la acción. Debería fundarse, creo, en las buenas consecuencias que tal diferenciación tiene para lo que se considera moralmente más valioso, que en el caso de la guerra es la minimización de muertes. El principio de inmunidad debería ser considerado entonces como una convención que, en virtud de su utilidad para minimizar los terribles efectos de las guerras, especialmente en pérdida de vidas humanas, debe ser mantenida y promovida con rotundidad16. ¿Cuáles serían esas ventajosas consecuencias de exigir que los soldados se inhiban de atacar a la población civil en los conflictos bélicos?

En primer lugar, cabe decir que cuando necesariamente hay que elegir entre matar (justamente) a combatientes y a no combatientes, será mejor dirigir la acción mortífera contra aquellos y no contra estos. Esto es así porque, dado el potencial mortífero y destructor del soldado enemigo, frente al nulo peligro que supone el civil desarmado, elegir la muerte de aquel siempre minimizará, en principio, los males de la guerra.

En segundo lugar, un principio de inmunidad que exige no matar intencionadamente a los no combatientes resulta muy satisfactorio porque hace a los soldados menos agresivos. Los rasgos de carácter, y en concreto las motivaciones, también pueden ser evaluados en virtud de su utilidad para el bien común. Y en nuestro caso, parece evidente que las guerras serán menos cruentas, $\mathrm{y}$ todos ganaremos, si los soldados adoptan en el enfrentamiento una convencida actitud más de diferenciar entre combatientes y no combatientes, que de calcular en todo momento si los objetivos militares podrían conseguirse buscando la muerte de civiles. Quienes estén convencidos de que en la guerra no todo vale, de que en esta también hay límites morales, como el principio de inmunidad, serán personas más sensibles al daño innecesario

matar al no combatiente no es lo moralmente decisivo cuando en ambos casos se prevé la muerte de este a causa de lo que uno hace.

16 Obviamente, lo que más reduciría las muertes sería que no existieran guerras. Aquí no no he planteado la cuestión, del ius ad bellum, de cuándo una guerra es justa. Si lo hubiera hecho desde la postura consecuencialista que defiendo, habría sostenido que lo correcto se correspondería con una actitud ante la guerra muy cercana al pacifismo. Hay pocas razones consecuenciales para apoyar la guerra. Si queremos la paz, ese estado de cosas en el que no se produce una destrucción masiva de lo más apreciado por los seres humanos, la vida, entonces lo mejor es no buscarla por medio de la guerra. Hacerlo sería contraproducente por la dinámica, a la que conduce toda guerra, de coerción por parte de los vencedores, y de venganza por parte de los vencidos; por el tremendo potencial destructivo de las armas actuales, tanto nucleares como convencionales; y por el carácter siempre impredecible de los conflictos militares. Aún así, es cierto que el pacifismo que se derivaría de esta determinación consecuencialista de la guerra justa no puede dejar de ser una exigencia contingente. A pesar de lo terrible de la guerra y de su ineficacia para alcanzar la paz, habría situaciones en las que aquella podría estar justificada: cuando fuera más terrible que no hubiera guerra; cuando, dadas las condiciones moralmente pésimas de genocidio o de sistemática violación de derechos básicos, poco habría que perder, y cuando dada la focalización del conflicto y la intervención de organismos multinacionales, se pudiera atenuar la probabilidad de extender el conflicto. 
y gratuito hacia los demás. Si los soldados asumen esto y, por tanto, están dispuestos a poner serios reparos a atentar contra la población civil, está claro que los efectos inmediatos de la guerra serán menos malos. Al igual que los efectos a largo plazo. Pues el sentimiento de venganza que cunde entre los vencidos tras la guerra, excelente caldo de cultivo para una futura continuación del enfrentamiento, será mucho menor cuando los vencedores han respetado el principio de inmunidad no habiendo llevando a cabo, por ejemplo, indiscriminados bombardeos de ciudades.

Todo esto en cuanto a la justificación alternativa que propongo del principio de inmunidad. Pero también querría resaltar ciertos aspectos necesarios para una buena comprensión de dicho principio, a los que normalmente no se les presta suficiente atención y que encajan perfectamente con la justificación que propongo. Cuando se evalúa, sobre todo desde instancias no filosóficas, la muerte de civiles como resultado de una acción militar se suele poner tanto énfasis en si ha habido intención o no de matar a los civiles que se olvidan otros requisitos, que también son importantes para una correcta aplicación del principio. Se suele pensar que si uno cumple con el requisito de no pretender la muerte del inocente, son irrelevantes, en términos de responsabilidad para uno, las dimensiones y el carácter de los negativos efectos colaterales. Sin embargo, eso no es así. Ni siquiera lo ha sido para la doctrina del doble efecto, que siempre ha mantenido, en el fondo, que la prohibición de pretender la muerte de civiles es una condición necesaria, pero no suficiente, de la acción aceptable. Así, quitar la vida de civiles de manera no premeditada será considerado un admisible efecto colateral de mi obrar sólo si antes se han satisfecho dos requisitos, de claro perfil consecuencialista, que suelen acompañar a esta doctrina marcadamente deontologista ${ }^{17}$. Uno de ellos es el requisito de necesidad, que prohíbe toda destrucción gratuita. Eso significa que una operación militar sólo será moralmente válida si no existe alguna alternativa con la que conseguir logros equivalentes a un menor coste en vidas y sufrimiento humano.

El otro requisito que debe tenerse en cuenta al aplicar la doctrina del doble efecto al ius in bello es el de proporcionalidad ${ }^{18}$. Para este, el grado de destrucción per-

\footnotetext{
17 Lo que la doctrina del doble efecto permite es aplicar un criterio absolutista a la acción y a las consecuencias pretendidas mientras exige, al mismo tiempo, una consideración consecuencialista de los efectos previstos pero no queridos. Puede defenderse entonces una prohibición categórica de matar al inocente porque aún cuando una negativa a matarle pudiera llevar a incluso peores consecuencias, como que miles de inocentes fueran asesinados por otros, éstas son consecuencias no pretendidas y por consiguiente, aunque por supuesto deberían ser evitadas si es posible, en ningún caso podrían pesar más que la prohibición ineludible de matar.

${ }^{18}$ Los principios de necesidad y proporcionalidad, y todas las reglas derivadas de estos, obtienen su razón última y su contenido del postulado utilitarista de que, en principio, es incorrecto destruir los bienes del mundo, incluidos los pertenecientes a los enemigos que han emprendido guerras injustas. Las cuestiones relativas al significado de las condiciones de proporcionalidad y necesidad, y su aplicación a la ética de la guerra, especialmente al ius in bello, han sido escasamente tratadas en el ámbi-
} 
mitido en persecución de un objetivo militar debe ser proporcional a la importancia del objetivo; es decir, que el daño no pretendido, pero previsto, a los no combatientes no puede ser excesivo. Así, uno no podría bombardear un objetivo de escasa importancia militar matando a un gran número de civiles y afirmar que estas muertes no importan porque no son intencionadas.

El principio de inmunidad, tal y como lo concibo aquí, puede, por tanto, restringir considerablemente los ataques tácticos que suponen la muerte de civiles. Quedaría preguntarse, por último, si los restringe suficientemente. Hemos visto que no todas las muertes no pretendidas de civiles pueden considerarse meros efectos colaterales (disculpables). Pero ¿qué hay de las muertes que sí se buscan? ¿Estarían prohibidas por la propuesta que defiendo? Es evidente que, de manera absoluta, no ${ }^{19}$. He argumentado que las razones que deben apoyar la prohibición de matar intencionadamente a civiles se basan en las buenas consecuencias que su seguimiento suele tener. Ahora bien, siempre quedaría abierta la posibilidad, se podría objetar, de que los hechos pudieran quitarnos la razón y de que en algún caso concreto lo mejor para globalmente salvar más vidas fuera que se buscara premeditadamente la muerte de civiles. ¿Deberíamos en tal caso desobedecer la mencionada prohibición?

to filosófico. Algunos de los autores que sí las han tratado son Hurka (2005) y (2008), McMahan (2004), Mellow (2006) y Statman (2011).

19 El absolutista mantiene que dicha prohibición debe ser respetada aunque "se hundan los cielos". Esto es inicialmente atractivo, pero si las consecuencias de proteger ese derecho fueran verdaderamente catastróficas, la mayoría estaría de acuerdo en que ese derecho debería ceder. Quizá sea eso lo que ha llevado a Walzer (1977) a plantear algunas excepciones a su defensa absolutista del principio de inmunidad. Él propone, en efecto, que siempre debe hacerse justicia, excepto cuando los cielos realmente vayan a hundirse. Para él, si surge una emergencia suprema, el derecho a la inmunidad de los no combatientes debe ceder, de manera que se les podría atacar intencionadamente (caps. 12, 16 y 17). Pero la posición de Walzer es inherentemente inestable y últimamente inaceptable. Como le ocurriría a cualquier otra propuesta absolutista que eche mano de este tipo de "cláusula de emergencia", se encuentra con el problema de cómo justificar que la última palabra, que la razón última para decidir si se es absolutista o no, la tenga el criterio consecuencialista de la magnitud de los daños. ¿No significa esto salirse, en última instancia, del absolutismo del que se parte? Además, como señala Arneson (2006), el problema del recurso a la cláusula de emergencia es que finalmente acaba permitiendo mucho más de lo que pretende, como que mueran civiles en circunstancias menos extremas (pp. 1245). Veámoslo en el caso de Walzer. Su criterio para saber cuándo hemos de recurrir a la cláusula es la consideración de que, en algunas circunstancias, la ratio del mal que uno provoca violando la inmunidad de los no combatientes sobre el mal que uno evita de esta manera es tan favorable como para que la violación esté justificada. Entonces cabe preguntarse que si está justificado, por ejemplo, matar a cien mil civiles inocentes para impedir el asesinato de un millón de personas, ¿por qué no es igualmente permisible atacar y matar a un civil inocente para impedir la muerte de diez personas? Cualquier ratio de mal perpetrado sobre mal evitado que justifique violar la inmunidad de los no combatientes en emergencia suprema debe igualmente justificar violaciones proporcionalmente más pequeñas, incluso donde ninguna emergencia suprema se avecina. Para otras críticas del recurso deontologista a la cláusula de emergencia, véase Davis (1991, pp. 304-5). 
La respuesta es que, por razones igualmente consecuenciales, normalmente uno no debería desobedecer dicha prohibición. Decíamos más arriba que una consecuencia positiva del principio de inmunidad era que los soldados serían más sensibles ante el sufrimiento de los indefensos y que esto evitaría muchas muertes durante la guerra y después de esta. Pero para que esto sea efectivo, tal actitud debe haber sido interiorizada; debe, por tanto, formar parte del carácter o la identidad moral del soldado. Y resulta que esto sólo se puede conseguir si el soldado no acepta como regla moral que en cada momento se elija aquella acción que minimiza la pérdida de vidas totales, considerando para ello incluso la opción de matar a civiles. Es decir, lo que debe ser evaluado consecuencialmente son las motivaciones y no cada una de las acciones posibles. Y esto se justifica, a su vez, recurriendo al criterio de hacer lo que conlleva mejores consecuencias. Pues es obvio que frente a una sociedad de agentes calculadores de todo lo que hacen, todos estaremos mejor en otra en la que sus miembros se rigen por estables rasgos de carácter que, a la larga, contribuirán al bien común, que requerirán pocos costes educativos y psicológicos, y que facilitarán una convivencia basada en la previsibilidad.

Aún así, podría replicarse que admitir excepcionalmente el incumplimiento del principio de inmunidad no significa necesariamente que este no se haya interiorizado. Un soldado puede reconocer, seguramente con mucho pesar, la justificación de la excepción y no diremos por ello que en su carácter se ha producido un cambio sustantivo. Y de ser así, sería esta actitud la óptima, aquella que maximizaría el bien, pues los agentes que se rigieran por ella se sentirían normalmente motivados a obrar según el principio, con las mencionadas ventajas que esto conlleva, al mismo tiempo que permitirían que, en casos extremos, este pueda desobedecerse en aras a salvar a mucha gente.

Creo que a esta réplica se le podría responder que ciertamente tal opción es una posibilidad, pero probablemente sólo una posibilidad teórica. Es cierto que a lo largo de la historia de la Humanidad muchas atrocidades han sido justificadas en virtud de su conveniencia para evitar males mayores. El ejemplo más claro en nuestra historia reciente estaría en la justificación consecuencial que se suele dar del bombardeo indiscriminado y arrasador de ciudades alemanas y japonesas al final de la II Guerra Mundial. Así, se sostiene que tales acciones fueron convenientes porque aceleraron el final de la guerra y, con ello, evitaron muchas más muertes. Pero esto dista mucho de ser cierto. Los hechos muestran que tales bombardeos respondían más a una mera estrategia política, o incluso a un sentimiento de venganza, que a una pretensión de adelantar el final de la guerra. No eran bombardeos necesarios para minimizar, como decían, las pérdidas humanas. Dadas las destructivas ofensivas de la aviación alemana sobre su territorio, los británicos sabían por experiencia propia que los bombardeos terroristas no debilitan la moral del país. Y en el caso de las bombas atómicas de Hiroshima y Nagasaki, lanzarlas no podía responder a una 
intención de adelantar el final de la guerra porque Japón ya estaba derrotado y a punto de rendirse. Además, suponiendo que hubieran contribuido al final de la guerra, los bombardeos aliados en Alemania y Japón eran claramente desproporcionados. Los británicos podrían haber destinado todo los recursos militares usados en los bombardeos para abrir un segundo frente en Francia, y los norteamericanos tenían la opción de conseguir los pretendidos efectos aterradores con una simple demostración de la nueva bomba arrojándola en zonas no pobladas. Con ambas acciones alternativas se hubiera conseguido adelantar el final de la guerra sin ocasionar la innecesaria muerte de casi un millón de civiles que provocaron los bombardeos. Si no lo hicieron fue por venganza y odio; o bien, como algunos han señalado en el caso de Japón, para que Truman, gracias a una rendición incondicional y rápida de este país, no tuviera que compartir los laureles y el botín de la victoria con la Unión Soviética, que estaba a punto de declarar la guerra al país nipón. Así, Truman obtendría de esta rendición tanto como Churchill y Stalin habían conseguido de la de Alemania20.

Lo que esta revisión de la lectura habitual de tales hechos viene a mostrar es que los bombardeos en los que se busca intencionadamente la muerte de civiles suelen ser innecesarios y desproporcionados. Tiene sentido, por tanto, mantener un principio de la inmunidad que exija a los combatientes que los civiles nunca sean su objetivo, y que cuando la muerte de estos sea un efecto colateral del ataque, siempre sea necesaria para la consecución del objetivo y proporcional a la importancia de este. Este principio debe ser concebido, entonces, como una norma que, en virtud de su utilidad para una mejor existencia y convivencia, se ha de seguir como si no tuviera excepciones. Creo que con esta forma alternativa de entender y justificar el principio de inmunidad se marcarían en el comportamiento bélico unos límites claros y plausibles con los que salvaguardar mejor aquello que más valoramos: la protección de la vida y la evitación del sufrimiento.

\section{Referencias bibliográficas}

AleXANDER, L. (1987): "Justification and Innocent Aggressors", Wayne Law Review, 33.

Alexander, L. (1993): "Self-Defense, Justification, and Excuse", Philosophy and Public Affairs, 22.

ARNESON, R.J. (2006): "Just Warfare Theory and Noncombatant Immunity", Cornell International Law Journal, 39.

\footnotetext{
${ }^{20}$ Lackey (1989, pp. 69-78). Para formarse un juicio informado de los datos históricos esenciales respecto al bombardeo atómico de Japón, véase, por ejemplo, Feis (1966) y Miles (1985).
} 
BenBAJI, Y. (2005): "Culpable Bystanders, Innocents Threats, and the Ethics of Self-Defense", Canadian Journal of Philosophy, 585.

DAVIS, N. (1991): "La deontología contemporánea", en P. Singer (ed.) (1991), Compendio de ética, Alianza Editorial, 1995.

DrAPER, K. (2009): "Defense", Philosophical Studies, 145.

FeIS, H. (1966): The Atomic Bomb and the End of World War II, Princeton University Press.

FERZAN, K.K. (2005): "Justifying Self-Defence", Law and Philosophy, 24.

Frowe, H. (2008): "Equating Innocent Threats and Bystanders", Journal of Applied Philosophy, 25.

Hurka, T. (2005): "Proportionality in the Morality of War", Philosophy and Public Affairs, 33.

HuRKA, T. (2008): "Proportionality and Necessity", en L. May (ed.)(2008), War: Essays in Political Philosophy, Cambridge University Press.

KADISH, S. (1976): "Respect for Life and Regard for Rights in the Criminal Law", California Law Review, 64.

Kamm, F.M. (1992): Creation and Abortion, Oxford University Press.

Kaufman, W. (2009): “Can 'Moral Responsibility' Explain Self-Defense?”, en P. Robinson et al. (eds.) (2009), Criminal Law Conversations, Oxford University Press.

LaCKey, D.P. (1989): The Ethics of War and Peace, Prentice Hall.

LeVerick, F. (2006): Killing in Self-Defence, Oxford University Press.

LichtenberG, J. (1994): "War, Innocence, and the Doctrine of Double Effect", Philosophical Studies, 74.

McMahan, J. (1994a): "Self-Defense and the Problem of the Innocent Attacker", Ethics, 104.

McMahan, J. (1994b): "Innocence, Self-Defense and Killing in War", Journal of Political Philosophy, 6.

McMahan, J. (2002): The Ethics of Killing. Problems at the Margins of Life, Oxford University Press.

McMahan, J. (2004): “The Ethics of Killing in War", Ethics, 114.

McMahan, J. (2005a): "The Basis of Moral Liability to Defensive Killing", Philosophical Issues, 15.

McMahan, J. (2005b): "Self-Defense and Culpability", Law and Philosophy, 24.

Mellow, D. (2006): "Counterfactuals and the Proportionality Criterion", Ethics and International Affairs, 20.

MiLES, R.E. (1985): "The Strange Myth of a Million Lives Saved", International Security, 10.

Montague, P. (1981): "Self-Defense and Choosing Among Lives", Philosophical Studies, 40. 
Montague, P. (1989): “The Morality of Self-Defense: A Reply to Wasserman", Philosophy and Public Affairs 18.

Montague, P. (2000): "Self-Defense and Innocence: Aggressors and Active Threats", Utilitas, 12.

Montague, P. (2010): "Self-Defense, Culpability, and Distributive Justice", Law and Philosophy, 29.

OтsuкA, M. (1994): "Killing the Innocent in Self-Defence", Philosophy and Public Affairs, 23.

QuONG, J. (2009): “Killing in Self-Defence”, Ethics, 119.

Rodin, D. (2003): War and Self-Defense, Oxford University Press.

Rodin, D. (2004): "War and Self-Defense", Ethics and International Affairs, 18.

Rodin, D. (2008): "The Moral Inequality of Soldiers: Why jus in bello Asymmetry Is Half Right" en D. Rodin y H. Shue (eds.) (2008), Just and Unjust Warriors, Oxford University Press.

Statman, D. (2011): "Can Wars Be Fought Justly? The Necessity Condition Put to the Test", Journal of Moral Philosophy, 8.

TAdros, V. (2009): "Doubts About the Responsibility Principle", en P. Robinson et al. (eds.) (2009), Criminal Law Conversations, Oxford University Press.

Thomson, J.J. (1991): "Self Defense", Philosophy and Public Affairs, 20.

UniaCKe, S. (1994): Permissible Killing, Cambridge University Press.

Uniacke, S. (2000a): "In Defence of Permissible Killing", Law and Philosophy, 19.

UNIACKE, S. (2000b): "Rights and Relativistic Justifications: Replies to Kasachkoff and Husak", Law and Philosophy, 19.

Wallerstein, S. (2009): "Why Causal Responsibility Matters", en P. Robinson et al. (eds.)2009, Criminal Law Conversations, Oxford University Press.

Walzer, M. (1977): Guerras justas e injustas, Paidós, 2001.

Walzer, M. (1985): “The Moral Standing of States”, en C. R. Beitz et al. (eds.) (1985), International Ethics, Princeton.

ZoHAR, N. (1993): "Collective War and Individualistic Ethics: Against the Conscription of "Self-Defense", Political Theory, 21.

Zohar, N. (2004): "Innocence and Complex Threats: Upholding the War Ethic and the Condemnation of Terrorism", Ethics, 114.

Francisco Lara

Departamento de Filosofía I

Universidad de Granada

flara@ugr.es 